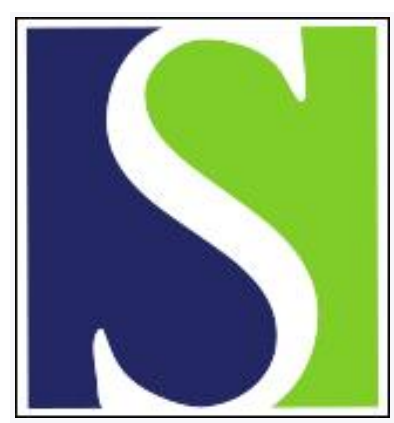

Scand J Work Environ Health 1987;13(2):146-149

https://doi.org/10.5271/sjweh.2076

Issue date: Apr 1987

Occupation, work load and the size and shape of lumbar vertebral canals.

by Vanharanta H, Heliovaara M, Korpi J, Troup JD

This article in PubMed: www.ncbi.nlm.nih.gov/pubmed/2955516

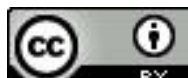




\title{
Occupation, work load and the size and shape of lumbar vertebral canals
}

\author{
by Heikki Vanharanta, MD, ${ }^{1}$ Markku Heliövaara, MD, ${ }^{2}$ Jussi Korpi, MD, ${ }^{3} \mathrm{~J}$ Duncan G Troup, $\mathrm{PhD}^{4}$
}

\begin{abstract}
VANHARANTA H, HELIÖVAARA M, KORPI J, TROUP JDG. Occupation, work load and the size and shape of lumbar vertebral canals. Scand $J$ Work Environ Health 13 (1987) 146-149. Measurements made from plain lumbar radiographs were used to compare the size and shape of the lumbar vertebral canals between various categories of occupation and work load among 77 men and 118 women with a history of low-back pain. The mean anteroposterior foraminal diameters proved to be wider in female farm workers than in other women, especially in the vertebra L3 $(17.1$ versus $15.4 \mathrm{~mm})$. However, the men who did heavy manual work had smaller anteroposterior foraminal diameters than the men whose work involved less physical labor (difference at L5 9.4 versus $10.8 \mathrm{~mm}$ ). Female farm workers were found to have shorter interarticular distances than females in other occupational groups. In the men who reported working in stooped postures or reported lifting and carrying heavy objects at work, the interarticular distances were wider than in men who had no such exposures.
\end{abstract}

Key terms: back pain, epidemiology, X-ray measurements.

The association between early degenerative changes in the lumbar spine and heavy manual work has long been recognized $(2,4)$. In those series $(2,4)$, back pain was increasingly frequent in the subjects with severe degenerative changes in the lumbar spine, but the changes, per se, were not necessarily symptomatic. More recently, clear-cut associations between narrow vertebral canals or foramina and the herniated lumbar disc syndrome have been found $(6,10)$. This development has focused attention on the radiographic appearance of these phenomena.

It has been shown that measurements of the size and shape of the lumbar spinal canal and foramina can be made consistently and repeatably $(5,7,9)$ and that there is a satisfactory relation between the radiographic and bony measurements (5). Baddeley (1) and Roberts (7) found that the interarticular distance, the midsagittal diameter, the pedicular length, and the anteroposterior diameter of the foramen were, clinically, the critical measurements, reporting significant differences between symptom-free subjects, patients with sciatic symptoms, and patients with the cauda equina syndrome.

1 Department of Physical Medicine and Rehabilitation, University of Helsinki, Finland.

2 The Research Institute for Social Security of the Social Insurance Institution, Helsinki, Finland.

3 Department of Physical Medicine and Rehabilitation, the Central Hospital of Seinäjoki, Finland, and the Rehabilitation Research Centre of the Social Insurance Institution, Turku, Finland.

${ }^{4}$ Department of Orthopaedic and Accident Surgery, University of Liverpool, England.

Reprint requests to: Dr M Heliövaara, Research Institute for Social Security, PO Box 78, SF-00381 Helsinki, Finland.
The size and shape of the vertebral canals are partly determined by congenital factors, but they are also dependent on age, sex, anthropometry, and degeneration $(5,7,9)$. Women have wider intervertebral foramina than men, but their interarticular distance is smaller. Narrowing in either of these two diameters is associated with signs of diminished lumbar mobility in both sexes however (9). Roberts (7) considered that degenerative changes shortened the interarticular distance and pedicular length and narrowed the foramen. The present study was made to investigate vertebral canal measurements in relation to occupation and history of work load.

\section{Subjects and methods}

The Mini-Finland Health Survey is an extensive epidemiologic project aimed at the comprehensive evaluation of the health of the population. The field work, including questioning, interviews and clinical examinations in three separate phases, lasted from 1977 to 1980 . The screening of low-back syndromes has been described in detail elsewhere (3). The subjects who reported low-back pain, back injury or sciatic pain with history of recurrence, significant disability, or permanent trouble were identified as candidates for this study through screening. About one year later, a sample of 234 persons from southwest Finland were then invited to take part in the particular low-back study, and 199 of these persons were clinically examined and radiographed. Four cases were rejected, three because of technically poor radiographs and one because of missing medical records. In all, 195 subjects $(83.3 \%$ of the sample, 119 women and 76 men) remained as subjects of this study. 
A questionnaire concerning occupation, physical activity at work, history of work posture and methods, and reproductive history (women) was sent to the subjects, together with an invitation to a medical checkup, for completion before the base-line field examination. The answers to this self-administered questionnaire were checked and completed, if necessary, by a specially trained nurse at the examination.

The exact title of the present or last occupation and a brief description of the work, as recorded in the questionnaire, were used in coding the occupations according to the Nordic Standard Classification of Occupations. In the present study, the subjects were classified into the following four main occupational groups: white-collar workers, farm workers, industrial workers, and service workers, including other small groups.

The subjects rated physical activity in their present work on a scale from 1 to 6 , each of the six degrees being characterized in the questionnaire by means of illustrative examples. The original classes were combined to produce the three categories of physical activity entitled "light," "moderate," and "heavy." The fourth category comprised the subjects who were occupationally inactive at the time of the base-line examination; they were excluded from the ad hoc analyses.

Questions about work load characteristics were asked both for the current or last occupation and the longest of previous occupations. The subjects answered "yes" or "no" concerning the lifting or carrying of heavy objects; stooped, twisted or otherwise awkward work postures; continuous standing; exposure to whole-body or upper-limb vibration; constantly repeated series of movements; and paced work. Exposure was considered present if the examinee recorded it for either the last or the longest of the occupations.

Radiographs of the lumbar spine of all the subjects were taken with a standardized technique, using a tube/film distance of $120 \mathrm{~cm}$. The frontal radiograph was obtained with the subject in the supine position, and the lateral view with the subject standing erect. A physiatrist who had not seen any of the patients or their clinical data made the following measurements from the radiographs (9): interarticular distance (L3 to $\mathrm{S} 1$ ), interpedicular distance (L3 to S1), midsagittal diameter (L3 to L5), anteroposterior foraminal distance (L3 to L5), and pedicular length (L3 to S1).

A general linear model was applied in the search for independent differences in vertebral measurements between the categories of the explanatory variables (8). Body height $(\mathrm{cm})$, body mass index $\left(\mathrm{kg} / \mathrm{m}^{2}\right)$, age (years), and parity of the women (number of childbirths) were included in the multifactorial model as potential confounders, as these variables were known to have close associations both with occupation and the radiological measurements. The results were expressed as adjusted mean values of the radiological measurements in various categories of occupation and work load, and the variation was tested with the F-test (8).

\section{Results}

Interpedicular distance, interarticular distance, and anteroposterior foraminal diameter were found to have a number of significant relationships with occupation or work load, but not the midsagittal diameter or pedicular length. Therefore exact results are presented only for the first three measurements mentioned.

\section{Occupational groups}

Among the men, no differences in the vertebral measurements were found between white-collar, agricultural, industrial, and service workers. Female farm workers were found to have a shorter interarticular distance than the other occupational groups at all levels of the lumbar spine (table 1); this difference proved to be statistically significant at L5 $(P=0.03)$. In contrast, female farm workers had the widest foramina, the difference in anteroposterior foraminal distance of these women and those of the other groups being

Table 1. Means $(\mathrm{mm})$ of the interarticular and anteroposterior foraminal distances in the women by occupation. The means have been adjusted with an analysis of covariance (age, body height, body mass index, and parity having been allowed for).

\begin{tabular}{|c|c|c|c|c|c|c|c|c|}
\hline \multirow[b]{2}{*}{ Measurement } & \multicolumn{5}{|c|}{ Occupational groups of women } & \multicolumn{3}{|c|}{ All groups combined } \\
\hline & $\begin{array}{l}\text { White- } \\
\text {-collar } \\
\text { workers } \\
(\mathrm{N}=39)\end{array}$ & $\begin{array}{c}\text { Farm } \\
\text { workers } \\
(\mathrm{N}=18)\end{array}$ & $\begin{array}{l}\text { Indus- } \\
\text { trial } \\
\text { workers } \\
(\mathrm{N}=29)\end{array}$ & $\begin{array}{l}\text { Service } \\
\text { workers } \\
(\mathrm{N}=32)\end{array}$ & P-value & $\begin{array}{c}\text { Farm } \\
\text { workers } \\
(\mathrm{N}=18)\end{array}$ & $\begin{array}{c}\text { Other } \\
\text { groups } \\
(\mathrm{N}=100)\end{array}$ & P-value \\
\hline \multicolumn{9}{|l|}{$\begin{array}{l}\text { Interarticular } \\
\text { distance }\end{array}$} \\
\hline $\begin{array}{l}\text { L3 } \\
\text { L4 } \\
\text { L5 } \\
\text { S1 }\end{array}$ & $\begin{array}{l}22.5 \\
22.6 \\
24.9 \\
30.6\end{array}$ & $\begin{array}{l}21.7 \\
21.5 \\
22.3 \\
28.4\end{array}$ & $\begin{array}{l}22.5 \\
22.1 \\
24.2 \\
30.0\end{array}$ & $\begin{array}{l}22.7 \\
22.7 \\
24.2 \\
29.6\end{array}$ & $\begin{array}{l}0.69 \\
0.62 \\
0.14 \\
0.60\end{array}$ & $\begin{array}{l}21.7 \\
21.5 \\
22.4 \\
28.5\end{array}$ & $\begin{array}{l}22.6 \\
22.5 \\
24.5 \\
30.1\end{array}$ & $\begin{array}{l}0.24 \\
0.26 \\
0.03 \\
0.26\end{array}$ \\
\hline \multicolumn{9}{|c|}{$\begin{array}{l}\text { Anteroposterior } \\
\text { foraminal distance }\end{array}$} \\
\hline $\begin{array}{l}\text { L3 } \\
\text { L4 } \\
\text { L5 }\end{array}$ & $\begin{array}{l}15.7 \\
14.0 \\
11.9\end{array}$ & $\begin{array}{l}17.1 \\
14.8 \\
12.5\end{array}$ & $\begin{array}{l}15.1 \\
12.9 \\
11.1\end{array}$ & $\begin{array}{l}15.4 \\
13.2 \\
10.8\end{array}$ & $\begin{array}{l}0.03 \\
0.07 \\
0.14\end{array}$ & $\begin{array}{l}17.1 \\
14.9 \\
12.6\end{array}$ & $\begin{array}{l}15.4 \\
13.4 \\
11.3\end{array}$ & $\begin{array}{l}0.005 \\
0.05 \\
0.09\end{array}$ \\
\hline
\end{tabular}


Table 2. Means ( $\mathrm{mm}$ ) of the anteroposterior foraminal distances in the men and women by physical activity at work. The means have been adjusted with an analysis of covariance (age, body height, and body mass index, along with the parity of the women, having been allowed for). The nine occupationally inactive men and 25 women have been excluded.

\begin{tabular}{|c|c|c|c|c|c|c|}
\hline \multirow[b]{3}{*}{ Level } & \multicolumn{6}{|c|}{ Physical activity at work } \\
\hline & \multicolumn{3}{|c|}{ Women } & \multicolumn{3}{|c|}{ Men } \\
\hline & $\begin{array}{l}\text { Light or } \\
\text { moderate } \\
(\mathrm{N}=76)\end{array}$ & $\begin{array}{c}\text { Heavy } \\
(N=17)\end{array}$ & P-value & $\begin{array}{l}\text { Light or } \\
\text { moderate } \\
(\mathrm{N}=38)\end{array}$ & $\begin{array}{c}\text { Heavy } \\
(N=30)\end{array}$ & P-value \\
\hline L3 & 15.6 & 16.4 & 0.19 & 15.1 & 14.2 & 0.21 \\
\hline L4 & 13.5 & 14.2 & 0.25 & 13.1 & 11.8 & 0.08 \\
\hline L5 & 11.4 & 12.4 & 0.21 & 10.8 & 9.4 & 0.01 \\
\hline
\end{tabular}

Table 3. Means (mm) of the interpedicular distances in the women by physical activity at work. The means have been adjusted with an analysis of covariance (age, body height, body mass index, and parity having been allowed for). The 25 occupationally inactive women have been excluded.

\begin{tabular}{lcccc}
\hline \multirow{2}{*}{ Level } & \multicolumn{2}{c}{ Physical activity at work } & \\
\cline { 2 - 4 } & $\begin{array}{c}\text { Light } \\
(\mathrm{N}=23)\end{array}$ & $\begin{array}{c}\text { Moderate } \\
(\mathrm{N}=53)\end{array}$ & $\begin{array}{c}\text { Heavy } \\
(\mathbf{N}=17)\end{array}$ & P-value \\
\hline L3 & 26.5 & 27.2 & 27.8 & 0.09 \\
L4 & 27.4 & 27.9 & 28.6 & 0.30 \\
L5 & 31.4 & 31.8 & 32.3 & 0.71 \\
S1 & 36.7 & 38.5 & 39.9 & 0.01 \\
\hline
\end{tabular}

Table 4. Means $(\mathrm{mm})$ of the interarticular distances in the men by history of stooped work posture. The means have been adjusted with an analysis of covariance (age, body height, and body mass index having been allowed for).

\begin{tabular}{lccc}
\hline \multirow{2}{*}{ Level } & \multicolumn{3}{c}{ History of stooped posture } \\
\cline { 2 - 4 } & $\begin{array}{c}\text { Yes } \\
(\mathrm{N}=47)\end{array}$ & $\begin{array}{c}\text { No } \\
(\mathrm{N}=30)\end{array}$ & P-value \\
\hline L3 & 25.7 & 24.5 & 0.06 \\
L4 & 25.2 & 24.3 & 0.25 \\
L5 & 28.8 & 27.1 & 0.04 \\
S1 & 35.5 & 33.1 & 0.06 \\
\hline
\end{tabular}

Table 5. Means (mm) of the interarticular distances in the men by history of frequent lifting or carrying of heavy objects. The means have been adjusted with an analysis of covariance (age, body height, and body mass index having been allowed for).

\begin{tabular}{lccc}
\hline & \multicolumn{3}{c}{ History of lifting or carrying } \\
\cline { 2 - 4 } Level & $\begin{array}{c}\text { Yes } \\
(\mathrm{N}=44)\end{array}$ & $\begin{array}{c}\text { No } \\
(\mathrm{N}=33)\end{array}$ & P-value \\
\hline L3 & 25.8 & 24.5 & 0.05 \\
L4 & 25.4 & 24.1 & 0.10 \\
L5 & 28.8 & 27.4 & 0.11 \\
S1 & 35.6 & 33.2 & 0.07 \\
\hline
\end{tabular}

statistically significant for L3 $(P=0.005)$ and L4 $(P=0.05)$. In the other occupational groups of women the vertebral measurements were similar.

\section{Physical activity at work}

The men who gave a history of heavy manual work had significantly smaller anteroposterior foraminal distances at L5 $(\mathrm{P}=0.01)$ than the men who rated their occupational physical activity as moderate or light (table 2), but no differences in the vertebral measurements were found between the "light" and "moderate" groups. A contrary tendency was seen for the anteroposterior foraminal diameters of the women (table 2), but the difference did not reach statistical significance. Among the women there was also a clearcut gradient in the interpedicular distance at all levels of the lumbar spine (table 3 ) so that the measurements were smallest in the females having reported light activity, but the variation proved significant only for S1 $(P=0.01)$.

\section{Work methods and posture}

Paced work. Eight men and 13 women had jobs entailing paced work; the remainder of the jobs were unpaced. Although the interpedicular distances of the men at L4 and L5 were 2.1 and $2.8 \mathrm{~mm}$ wider, respectively, than the corresponding distances of those engaged in paced work, the differences, when corrected, were not statistically significant. No other measurements of the men, and none of the women's showed significant differences.

Repetitive movements at work. There were 24 men and 36 women whose work involved repetitive movements, but there were no differences in their vertebral measurements in comparison with those of workers not doing such work.

Stooped posture. In 47 men whose work required stooped, twisted or otherwise awkward postures, the interarticular distance was found to be wider at all levels (table 4), but statistical significance was reached only for L5 (P=0.04). In no other measurements of the men, and in none of the women's (64 exposed), were there any significant differences in stooped and nonstooped postures between the workers.

Lifting or carrying of heavy objects. The interarticular distances were found to be wider in men exposed to heavy lifting or carrying (table 5), but the difference reached statistical significance only for $L 3(P=0.05)$. Among the women there were no differences between the two groups (63 exposed and 55 unexposed).

Vibration. There were no significant differences in the measurements of the subjects exposed to vibration $(25$ men and 6 women) and those who were not. 


\section{Discussion}

Osteoarthrosis, with its attendant hypertrophy, tends to diminish the space available within the canal and foramina, and this phenomenon is etiologically distinct from the dimensions which are genetically determined. The link between such degenerative changes and occupation $(2,4)$ was established a generation ago and may still be valid today. When it arises, it can be predicted that the interarticular distance will narrow as the hypertrophic changes affecting the superior articular facets encroach medially and that the anteroposterior foraminal diameters will be reduced by encroachment posterolaterally from the vertebral body margin and, to some extent, by facetal hypertrophy.

Hypothetically, it was therefore to be expected that, where the occupational work load increased the risk of osteoarthrosis, the radiographic measurements would be reduced. This hypothesis proved to be so for one measurement of the men, the anteroposterior foraminal diameter at $\mathrm{L} 5$, in those who perceived their physical activities at work to be "heavy." It also held for the interarticular distance of the female farm workers, at L5, an indication that farm work is perceptibly heavier than other female occupations. These two measurements, anteroposterior foraminal distance in men and interarticular distance in women, have been associated with clinical evidence of restricted lumbar mobility (9).

The fact that there were no other confirmatory relationships between radiographic narrowing and physical stress at work is, however, not surprising, for the subjects did not represent an occupational crosssection of the population but was, instead, restricted to a sample with significant back pain. All either had, or had previously suffered, back pain. It could therefore be postulated that those who regularly stooped, lifted and carried at work or who were ex- posed to repetitive movements or vibration were less severely affected by symptoms than the remainder who did not expose themselves to such occupational stresses. From this standpoint, the wider interarticular distances of the men who regularly lifted, carried or stooped would be a reasonable finding. In addition other explanations than the "wear and tear" phenomenon are possible. What is needed is a longitudinal epidemiologic study of a wider sample of the population.

\section{References}

1. Baddeley H. Radiology of lumbar spine. In: Jayson M, ed. The lumbar spine and back pain. Sector Publishing Limited, London 1976, pp 151-171.

2. Hult L. Cervical, dorsal and lumbar spine syndromes. Acta Orthop Scand Suppl 17 (1954) 1-102.

3. Korpi J. Alaselän sairaudet Lounais-Suomen aikuisväestössä [Low back diseases in the adult population of southwest Finland]. Social Insurance Institution, Turku (Finland) 1982. (Publications of the Social Insurance Institution AL: 19) (English summary).

4. Lawrence JS. Disc degeneration: Its frequency and relationship to symptoms. Ann Rheum Dis 28 (1969) $121-138$

5. Leiviskä $T$, Videman $T$, Nurminen $T$, Troup JDG. Radiographic versus bony measurements of the spinal canal at lumbar vertebrae L3-L5 and their relations to age and body stature. Acta Radiol Diagn 26 (1985) 1-9.

6. Porter RV, Hibbert CS, Wicks M. The spinal canal in symptomatic lumbar disc lesions. J Bone Joint Surg 60-B (1978) 485-487.

7. Roberts GM. Lumbar stenosis. University of London, London 1978. (Doctoral dissertation).

8. Searle SR. Linear models. Wiley, New York, NY 1971.

9. Vanharanta $\mathbf{H}$, Korpi J, Heliövaara M, Troup JDG. Radiographic measurements of lumbar spinal canal and their relation to back mobility. Spine 10 (1985) 461-466.

10. Winston $\mathrm{K}$, Rumbaugh $\mathrm{C}$, Colucci V. The vertebral canals in lumbar disc disease. Spine 9 (1984) 414-417.

Received for publication: 31 October 1986 